\title{
Investigating the Effect of Lockdown During COVID-19 on Land Surface Temperature: Study of Dehradun City, India
}

\author{
Sandeep Maithani ${ }^{1}$ (D) Garima Nautiyal ${ }^{2} \cdot$ Archana Sharma $^{2}$
}

Received: 30 June 2020 / Accepted: 24 August 2020/Published online: 5 September 2020

(C) Indian Society of Remote Sensing 2020

\begin{abstract}
Urban environment imposes challenges due to its dynamics and thermodynamic characteristics of the built environment. The present study aims to study the effect of lockdown during COVID-19 on the spatio-temporal land surface temperature (LST) patterns in Dehradun city. The TIRS sensor data of 14 April 2020 (post-lockdown), 28 April 2019, 25 April 2018 and 08 May 2017 were downloaded, and LST was retrieved using radiative transfer equation. The wardwise change in LST, urban hot spots and thermal comfort was studied as a function of built-up density. It was observed that there was an overall decrease in LST values in Dehradun city in post-COVID lockdown period. Wards with high built-up density had minimum decrease in LST; on the contrary, wards with large proportion of open spaces and having low, medium built-up density had the maximum decrease in LST. Hot spot analysis was carried out using Getis Ord GI* statistic, and the level of thermal comfort was found using the urban thermal field variance index. It was observed that there was an increase in number of hot spots accompanied by a decrease in thermal comfort level post-lockdown. The methodology proposed in the present study can be applied to other Indian cities which exhibit similar growth patterns and will provide a tool for rational decision making.
\end{abstract}

Keywords Land surface temperature - Thermal infrared sensor - Radiative transfer equation · Hot spot $\cdot$ Land surface emissivity $\cdot$ Urban thermal field variance index

\section{Introduction}

The urban growth process can be classified broadly into two modes: urban densification and urban sprawl. Urban densification refers to the increase in the building density in existing built-up areas, while urban sprawl refers to the outward growth of built-up areas on to the contiguous agricultural lands. (Wang and Upreti 2019; Rahman et al. 2011). Both the growth modes result in the conversion of

Sandeep Maithani

maithanis99@gmail.com

Garima Nautiyal

garimanautiya1065@gmail.com

Archana Sharma

doonarchana@gmail.com

1 Urban and Regional Studies Department, Indian Institute of Remote Sensing, Dehradun, India

2 School of Environment and Natural Resources, Doon University, Dehradun, India natural land cover (vegetation and pervious areas) into impervious built-up surfaces. The impervious built-up surfaces consist of building material like bitumen, asphalt, brick, concrete, etc. which absorb and store solar radiations during the day and release it gradually at night. Due to the intrinsic nature of building materials (i.e. radiative, thermal, moisture and emission characteristics), external parameters of the built-up areas (i.e. built-up density, urban geometry, orientation of buildings) and near-surface anthropogenic source of heat, the land surface temperature (LST) in urban areas is modified. This peculiar thermal behaviour of urban areas has significant consequences on human discomfort, energy consumption, air pollution levels and urban heat island (UHI) phenomena besides imposing challenges to landscape planning and resource management (Mathew et al. 2016, 2017; Mukherjee et al. 2017; Kikon et al., 2016; Mallick et al. 2013; Xu et al. 2012; Imhoff, et al. 2010; Yuan \& Bauer 2007; Gallo et al. 1993; Oke 1982). 
Thermal remote sensing data have been widely utilized for retrieval of LST, in comparison with ground sensors, due to its high spatial density. The LST retrieval algorithms are based on inversion of Planck's law and calculate brightness temperature from atmospheric radiances obtained from thermal infrared sensors (Mathew et al. 2016). The brightness temperature is then converted to LST using ground surface emissivity which accounts for water content, surface roughness and thermal properties of ground surface. The commonly used LST derivation algorithms are radiative transfer equation, single-channel algorithm, mono-window algorithm, split-window algorithm and multiple-angle algorithm. In the present study, the radiative transfer equation (RTE) has been used for LST retrieval due of its ease of implementation, and secondly, most of the input parameters in RTE can easily be estimated using the Atmospheric Correction Parameter Calculator which is located on the web at https://landsat. gsfc.nasa.gov/atm_corr (Barsi et al. 2003). The domain of the present study is Dehradun city which is a foothill urban centre located in Himalayan state of Uttarakhand, India. It is a fast-growing city with a population of 5,69,578 as per census of India 2011 (Census of India 2011) and has emerged as an important business, educational and cultural destination after becoming the capital of Uttarakhand state in year 2000 .

Dehradun city was put under complete lockdown for twenty-one days (i.e. from 25 March 2020 till 14 April 2020) for the containment of the COVID-19 outbreak. During this time period, commercial, industrial and vehicular activities were prohibited. As an aftermath, the near-surface anthropogenic emission of thermal energy and air pollution were significantly reduced. Improvement in air and water quality, and reduction in LST over different Indian cities during the lockdown period have been reported by various Indian authors. Siddiqui et al. (2020) reported an average reduction of $46 \%$ in concentration of $\mathrm{NO}_{2}$ and $27 \%$ improvement in air quality index over 8 five million plus cities of India due to the closure of industrial and construction activities. Mahato et al. (2020) reported reduction in the concentration of PM10, PM 2.5, $\mathrm{SO}_{2}, \mathrm{NO}_{2}$, $\mathrm{CO}, \mathrm{O}_{3}$ and $\mathrm{NH}_{3}$ gases over Delhi during lockdown period using data collected from 34 monitoring stations. Chauhan and Singh (2020) compared the PM 2.5 concentration in March 2020 and March 2019; the results showed a reduction of 35\% in Delhi and 14\% in Mumbai. Mitra et al. (2020) also studied the reduced level of $\mathrm{CO}_{2}$ at twelve sites in Kolkata city. Sharma et al. (2020) analysed the reduction in air pollutants in 22 cities of India. Kotnala et al. (2020) observed a significant improvement in Delhi ambient air quality due to lockdown. Srivastava et al. (2020) also reported a decline in $\mathrm{PM} 2.5, \mathrm{NO}_{2}$ and $\mathrm{CO}$ concentration in Delhi and Lucknow. Lal et al. (2020) explored the atmospheric pollutants reduction due to lockdown at global level. Mandal and Pal (2020) also explored the variation of PM 2.5 concentration in Dwarka river basin within Jharkhand and West Bengal. Kumar et al. (2020) compared the PM 2.5 levels over five Indian cities and reported that Indian cities showed up to $50 \%$ reductions in PM 2.5 concentrations. Kumar (2020) reported a decrease in the concentration in aerosols (AOD) and other pollutants $\left(\mathrm{NO}_{2}\right)$ at India level during the lockdown period. Lokhandwala and Gautam (2020) reported a remarkable reduction of $85.1 \%$ in PM 2.5 concentration in Ghaziabad which is one of the India's most polluted cities. A decrease in value of $\mathrm{CO}, \mathrm{SO}_{2}$ and ozone was also reported by Gupta et al. (2020) over Delhi. Bera et al. (2020) studied the air quality over Kolkata city and found that the level of pollutants like $\mathrm{CO}, \mathrm{NO}_{2}$ and $\mathrm{SO}_{2}$ had significantly decreased during the lockdown and there was a $17.5 \%$ reduction in PM10 and PM 2.5 concentration.

Kant et al. (2020) reported an average reduction of 20-37\% in aerosol optical depth (AOD) levels over eastern Indo-Gangetic planes, peninsular India and North India during the COVID-19 lockdown period.

Vaibhav et al. (2020) studied the changes in water quality during the lockdown period in river Ganges at Haridwar, Kanpur, Prayagraj and Varanasi. The results showed a decrease in turbidity in the river mainly due to less effluent generation and discharge. Mandal and Pal (2020) reported a reduction in total dissolve solid (TDS) level in river water adjacent to crushing unit in Dwarka river basin within Jharkhand and West Bengal. Lokhandwala and Gautam (2020) stated that river Ganga, Yamuna and Cauvery have become clean and clear and marine life was visible in the lockdown period. Selvam et al. (2020) stated that there was improvement in the groundwater quality in coastal industrial city of Tuticorin due to reduced industrial activity in lockdown period.

Mandal and Pal (2020) reported a reduction in LST values of $3-5{ }^{\circ} \mathrm{C}$ due to reduced anthropogenic activities in Dwarka river basin within Jharkhand and West Bengal. Ghosh et al. (2020) also stated a decreasing trend of LST values in their study of four Indian metro cities.

In view of the above discussion, in order to evaluate the effect of COVID-19 lockdown on surface temperature, the remote sensing-extracted LST values over Dehradun city on 14 April 2020 were compared with the near anniversary LST values of 28 April 2019, 25 April 2018 and 08 May 2017. Thermal remote sensing data acquired by thermal infrared sensor (TIRS) abroad Landsat 8 were used for LST retrieval on all four dates.

A number of studies have been reported by various authors for defining the relationship between LST and land cover using different indices, namely normalized difference vegetation index (NDVI), normalized difference built- 
up index (NDBI) and normalized difference water index (NDBI), as these indices represented the land-cover types quantitatively (Mathew et al., 2016, 2017; Ali et al., 2017). However, Tran et al. (2017), Guo et al. (2015) and Ao and Ngo (2000) reported building density as a crucial factor in urban LST studies as it is associated with the thermal properties of the existing structures and urban geometry. Thus, in the present study the built density classes were defined, and subsequently, the LST and hot spot trends, and thermal comfort levels in these built density classes were investigated.

\section{Study Area}

Dehradun city is located between $30^{\circ} 15^{\prime}$ and $30^{\circ} 25^{\prime}$ north latitudes and $78^{\circ}$ and $78^{\circ} 10^{\prime}$ east longitudes (Fig. 1a). It is surrounded by river Song on the east, river Tons on the west, Himalayan ranges on the north and Siwalik range in the south. During the summer months, the temperature ranges between $36{ }^{\circ} \mathrm{C}$ and $16.7{ }^{\circ} \mathrm{C}$. The winter months are colder with the maximum and minimum temperatures touching $23.4^{\circ} \mathrm{C}$ and $5.2^{\circ} \mathrm{C}$, respectively. Dehradun experiences heavy to moderate showers during late June to mid-August. Most of the annual rainfall (about $2000 \mathrm{~mm}$ ) is received during the months from June to September. July and August are the rainiest months of the season.

The city is divided into sixty administrative units (wards) demarcated on the basis of population density (Fig. 1b). The results of the present study were analysed at the ward level, since in Indian cities, ward is the smallest administrative unit at which all socio-economic and physical data are collected.

The wards located in the inner periphery of the city have mixed land use consisting of commercial and residential activities. The wards on the city periphery are mainly residential in nature with an intermixing of built-up and open spaces. The growth of city during the period 2017-2018 (period A), 2018-2019 (period B) and 2019-2020 (period C) was mainly in the form of densification of built-up areas by the conversion of open spaces to built-up. In fringes, growth was mainly sprawling in nature due to the conversion of agricultural lands to built-up areas. The lack of adequate infrastructure facilities in fringe areas has increased the travel trips of the fringe population to the city core. This increased vehicular movement coupled with reduced evapotranspiration (due to the conversion of open spaces to built-up) and urban geometry (i.e. urban canyons, orientation of buildings, disruption of wind flow) is among the main reasons contributing to elevated LST level over the city area. The strategic areas in the city and water bodies were masked out and not considered in the study.

\section{Data and Methodology}

\section{Data Used}

The thermal remote sensing data acquired by thermal infrared sensor (TIRS) abroad Landsat 8 were used for LST
Fig. 1 a Thematic sensor (TM) data of Dehradun city-2020. b Dehradun ward boundaries along with ward number

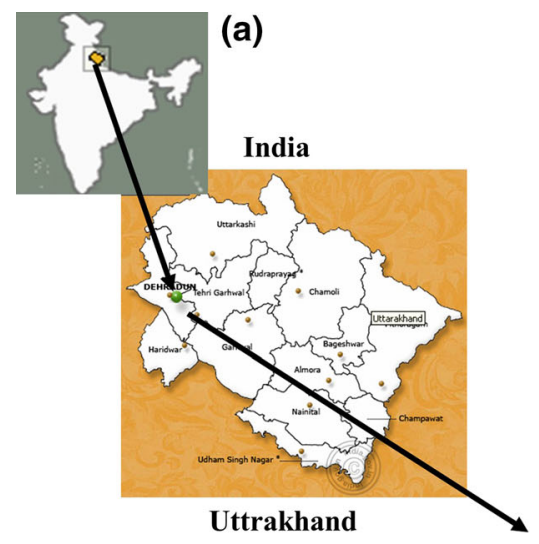

Dehradun city

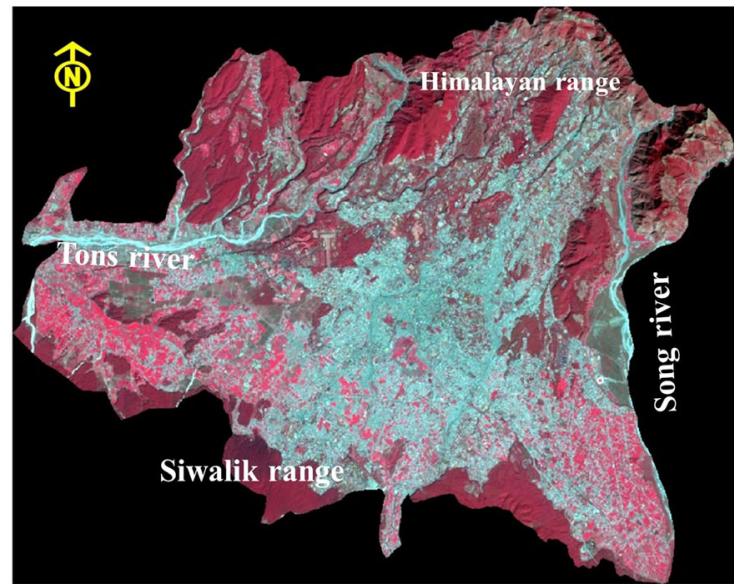


Fig. 1 continued

(b)

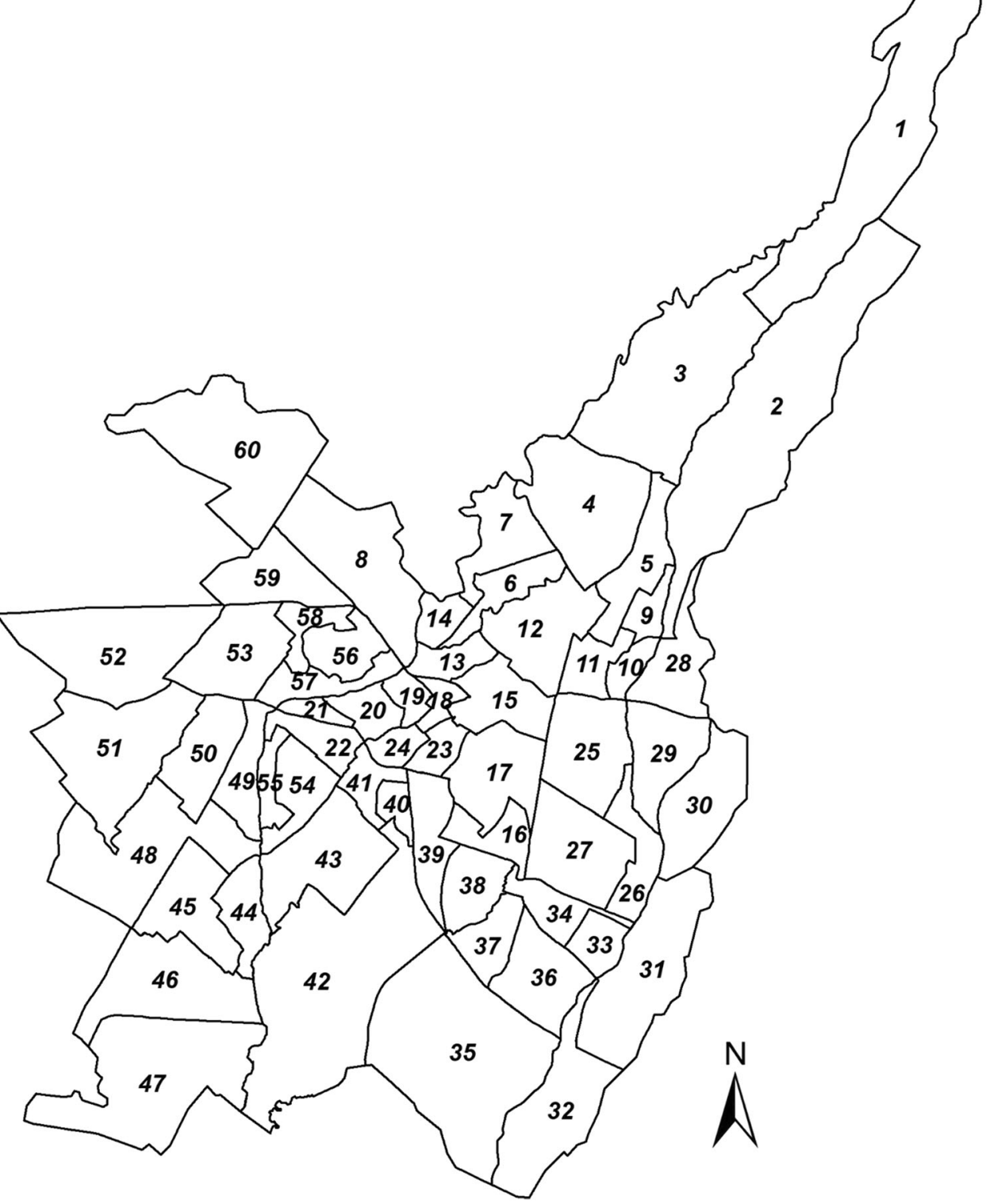

retrieval. TIRS consists of two thermal bands: Band 10 $(10.6-11.2 \mu \mathrm{m})$ and Band $11(11.5-12.5 \mu \mathrm{m})$. The data are collected originally at $100 \mathrm{~m}$ spatial resolution, but are resampled at $30 \mathrm{~m}$ and are freely downloadable from USGS Earth Explorer data portal website (https://earth explorer.usgs.gov/). In the present study, Band 10 was utilized for LST calculation as Band 11 has calibration uncertainty due to stray light contamination (Yu et al. 2014). TIRS Band 10 data were downloaded for dates: (a) 14 April 2020, (b) 28 April 2019, (c) 25 April 2018 and (d) 08 May 2017 (hereafter referred as year 2020, 2019, 2018 and 2017).
Multi-spectral images from operational land imager (OLI) sensor abroad Landsat 8 (having a spatial resolution of $30 \mathrm{~m}$ and three spectral bands, namely green $(0.525-0.600 \mu \mathrm{m})$, red $(0.630-0.68 \mu \mathrm{m})$ and near-infrared $(0.845-0.885 \mu \mathrm{m}))$ were used for generating the NDVI and land-cover maps. The ward boundary maps were made available by Dehradun city authority.

\section{LST Retrieval Using RTE Algorithm}

In the present study, the radiative transfer equation (RTE) was used for calculating the LST. As discussed in Sect. 1, 
the algorithm was chosen due to its simplicity and ease of implementation. The RTE was applied to Band 10 (10.6-11.2 $\mu \mathrm{m})$ of TIRS sensor. The steps followed in LST retrieval are as follows (Mallick et al. 2012; Yu et al. 2014; Wang et al. 2015 Sobrino et al. 2004, Sobrino and Romaguera 2004).

\section{Conversion of DN Values to at-Sensor Radiance}

$L_{\text {sensor } \lambda}=M_{L} * \mathrm{DN}+A_{L}$

where $L_{\text {sensor } \lambda}=$ spectral radiance $\left(\mathrm{W} /\left(\mathrm{m}^{2} * \mathrm{sr} * \mu \mathrm{m}\right)\right)$, $M_{L}=$ radiance multiplicative scaling factor for Band $10=0.0003342$ (retrieved from Landsat 8 metadata file), $A_{L}=$ radiance additive scaling factor for Band $10=0.1$ (retrieved from Landsat 8 metadata file) and DN = digital number.

\section{Estimation of Land Surface Emissivity $\left(\varepsilon_{\lambda}\right)$ from NDVI Threshold method (NDVI ${ }^{\mathrm{THM}}$ )}

The NDVI ${ }^{\mathrm{THM}}$ algorithm uses NDVI threshold values to distinguish between soil pixels (NDVI < 0.2 ) and vegetation cover (NDVI $>0.5)$. This method obtains the emissivity values from the NDVI considering three different cases (Yu et al. 2014; Sobrino et al. 2008; Griend and Owe 1993),

$\varepsilon=\left\{\begin{array}{cc}0.973-0.047 p_{\text {red }} & \mathrm{NDVI}<0.2 \\ \varepsilon_{v, i} P_{v}+\varepsilon_{s, i}\left(1-P_{v}\right)+C & 0.2 \leq \mathrm{NDVI} \leq 0.5 \\ \varepsilon_{v, i}+C & \mathrm{NDVI}>0.5\end{array}\right.$

where

(a) $p_{\text {red }}$ is the reflectivity in the red band.

(b) $\varepsilon_{V}$ is the emissivity of vegetation and $\varepsilon_{S}$ is the emissivity of the soil. Values of $\varepsilon_{V}=0.9863$ and $\varepsilon_{S}=$ 0.9668 were used based on Yu et al. (2014).

(c) $P_{V}$ is the proportion of the vegetation as defined in Eq. 3

$P_{V}=\left[\frac{\mathrm{NDVI}-\mathrm{NDVI}_{\min }}{\mathrm{NDVI}_{\max }-\mathrm{NDVI}_{\min }}\right]^{2}$

where $\mathrm{NDVI}_{\max }=0.5$ and $\mathrm{NDVI}_{\text {min }}=0.2$

(d) The term $C$ takes the cavity effect into account due to surface roughness. Sobrino and Raissouni 2000 suggested that $C$ can be estimated as follows,

$C=\left(1-\varepsilon_{S}\right)\left(1-P_{V}\right) F \varepsilon_{V}$

where $F$ is a geometrical factor ranging from 0 to 1 , depending on geometrical distribution of surface. A mean value of $F=0.55$ (Yu et al. 2014) was chosen for different distributions of surface roughness.
Calculation of Radiance Values Using Radiative Transfer Equation

$$
\begin{array}{r}
L_{\text {sensor } \lambda}=\left[\varepsilon_{\lambda} B_{\lambda}\left(T_{S}\right)+\left(1-\varepsilon_{\lambda}\right) L \downarrow_{\mathrm{atm}}\right] T_{\lambda}+L \uparrow_{\mathrm{atm}} \\
B_{\lambda}\left(T_{S}\right)=\left(L_{\text {sensor }}-T_{\lambda}\left(1-\varepsilon_{\lambda}\right) L \downarrow_{\mathrm{atm}}-L \uparrow_{\mathrm{atm}}\right) / T_{\lambda *} \varepsilon_{\lambda}
\end{array}
$$

where $L_{\text {sensor }}$ is the at-sensor radiance (Watts $/\left(\mathrm{m}^{2} * \mathrm{sr} *\right.$ $\mu \mathrm{m})), \varepsilon$ is the land surface emissivity, $B\left(T_{\mathrm{S}}\right)$ is the black body radiance at temperature $T_{\mathrm{S}}(\mathrm{K}) . \mathrm{L} \downarrow_{\text {atm }}$ is the downwelling atmospheric radiance (Watts/( $\left.\left.\mathrm{m}^{2} * \mathrm{sr} * \mu \mathrm{m}\right)\right), L \uparrow_{\mathrm{atm}}$ is the upwelling atmospheric radiance (Watts $/\left(\mathrm{m}^{2} * \mathrm{sr} *\right.$ $\mu \mathrm{m})$ and $T$ is the total atmospheric transmissivity between the surface and the sensor.

The atmospheric parameters $T, L \downarrow_{\text {atm }}$ and $L \uparrow_{\text {atm }}$ were estimated using the Atmospheric Correction Parameter Calculator (ACPC) which is located on the web at https:// landsat.gsfc.nasa.gov/atm_corr (Barsi et al. 2003). The ACPC uses commercially available MODTRAN software, National Centre for Environmental Prediction (NCEP) modelled atmospheric profiles and a suite of integration algorithms, to determine site-specific atmospheric transmission, upwelling and downwelling radiance.

\section{Conversion of Radiance Value $B\left(T_{S}\right)$ to LST}

The radiance value calculated in Eq. (5) was converted to LST using the relationship given in Eq. (6) (Isaya Ndossi and Avdan 2016). The relationship is similar to the Plank equation with two prelaunch constants $\mathrm{K}_{1}$ and $\mathrm{K}_{2}$

$$
T_{b}=\frac{\mathrm{K}_{2}}{\ln \left(\frac{\mathrm{K}_{1}}{B\left(\mathrm{~T}_{\mathrm{S}}\right)}+1\right)}
$$

where $T_{\mathrm{S}}=$ land surface temperature (LST), in Kelvin (K). $B\left(T_{\mathrm{S}}\right)=$ spectral radiance $\left(\right.$ Watts $\left./\left(\mathrm{m}^{2} * \mathrm{sr} * \mu \mathrm{m}\right)\right), \mathrm{K}_{1-}$ $=$ thermal conversion constant for Band $10=774.8853$ (retrieved from Landsat 8 metadata file) and $\mathrm{K}_{2}=$ thermal conversion constant for Band $10=1321.0789$ (retrieved from Landsat 8 metadata file).

The LST maps of year 2017, 2018, 2019 and 2020 were retrieved using the above-discussed procedures (Fig. 2).

\section{Characterization of Urban Spatial Structure}

The urban spatial structure was defined in terms of built-up densities, which was defined as the percent of built-up area in a circular neighbourhood of $1 \mathrm{~km}^{2}$ of each pixel. Thus, the urban spatial structure was defined in terms of four classes (Angel et al. 2012; Jason et al. 2009):

1. Urban high density: Built-up pixels with built-up density $>50 \%$ 


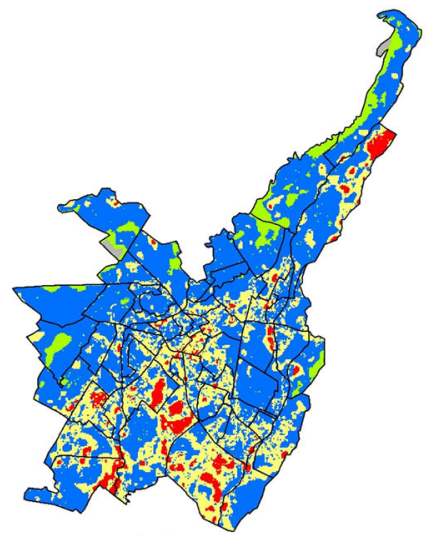

(a)

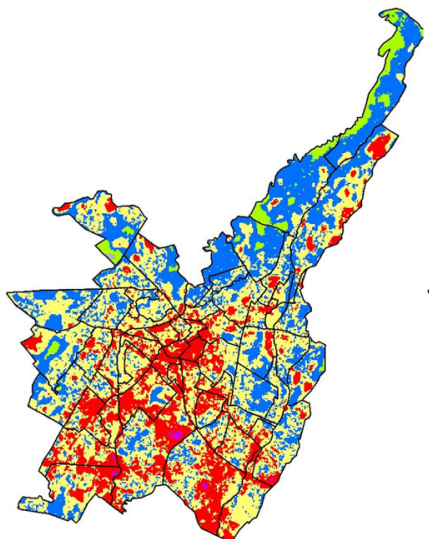

(b)

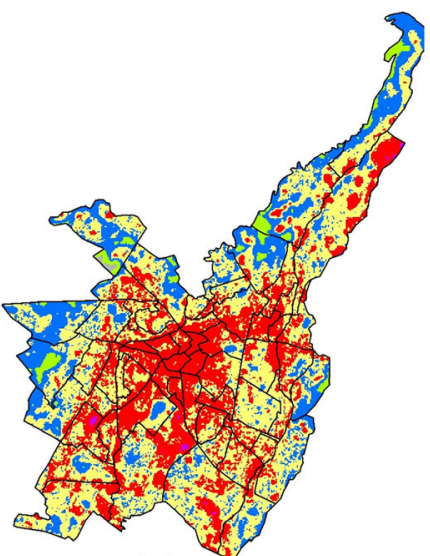

(c)

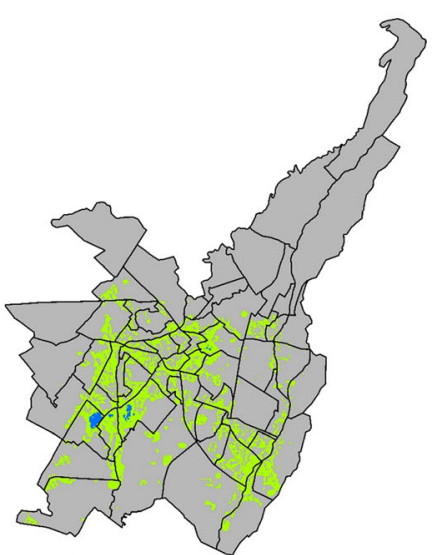

(d)

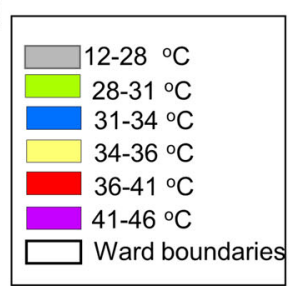

Fig. 2 Wardwise LST distribution in Dehradun city a 08 May 2017, (b) 25 April 2018, (c) 28 April 2019, (c) (d) 14 April 2020

2. Urban medium density: Built-up pixels with built-up density 30-50\%

3. Urban low density: Built-up pixels with built-up density $<30 \%$

4. Municipal open space: Non-built-up pixels located within city boundary

For delineating the four urban spatial structure classes, land-cover map of the respective years depicting built-up/ non-built-up areas served as the required input. Multispectral images from OLI sensor (having a spatial resolution of $30 \mathrm{~m}$ and three spectral bands, namely green $(0.525-0.600 \mu \mathrm{m})$, red $(0.630-0.68 \mu \mathrm{m})$ and near-infrared $(0.845-0.885 \mu \mathrm{m}))$ were used for generation of land-cover maps. The classification system consisted of three classes, viz. built-up, non-built-up and water bodies. The images were classified using the maximum likelihood classifier. The number of training samples taken for each class was 30n (Mather 1999; Fan et al. 2008), where $\mathrm{n}$ is the number of spectral bands. Since three spectral bands were used, the number of training samples taken in each class (i.e. builtup, non-built-up) was 90. The histogram plots of the training dataset for each class were unimodal in nature (Arora 2002). In order to determine the accuracy of classification, testing samples for each of the three classified classes were compared with the corresponding samples on reference data. Google Earth images of higher spatial resolution were used as a reference data. The number of testing samples selected per class for accuracy assessment was 50 (Congalton 1991; Congalton and Green 1999). A stratified random sampling was used for selecting the 50 testing pixels. The overall accuracy for the classified images was more than the minimum overall accuracy criteria of $85 \%$, as recommended by Anderson et al. (1976).

\section{Urban Thermal Field Variance Index (UTFVI)}

The UTFVI was estimated using the following equation (Guha et al. 2017, 2018; Zhang 2006)

$\mathrm{UTFVI}=\frac{T_{\mathrm{S}}-T_{\text {mean }}}{T_{\text {mean }}}$

where $T_{\mathrm{S}}$ is the $\operatorname{LST}\left({ }^{\circ} \mathrm{C}\right)$ and $T_{\text {mean }}$ is the mean $\operatorname{LST}\left({ }^{\circ} \mathrm{C}\right)$. Subsequently, the UTFVI values were classified into six ecological evaluation indices (EEI) (Table 1) (Zhang 2006), which were used for evaluating the level of thermal comfort.

\section{Results}

As discussed in Sect. 2, since ward is the smallest administrative unit in a city at which all data are aggregated, the LST patterns, hot and cold spots and the UTFVI values were analysed at the ward level.

\section{Temporal Analysis of Wardwise LST}

The LST values in each of the sixty wards (i.e. average LST value in each ward) for year 2017, 2018, 2019 and 2020 are shown in Fig. 3b. The solar radiation, precipitation or other atmospheric parameters remained almost the 
Table 1 Percentage of area in Dehradun city occupied by different classes of Ecological Evaluation index on 08 May 2017, 25 April 2018, 28 April 2019 and 14 April 2020

\begin{tabular}{llrrrr}
\hline UTFVI & Ecological Evaluation Index $($ EEI) & \multicolumn{3}{l}{ Percentage of area $(\%)$} \\
\cline { 3 - 6 } & & 2017 & 2018 & 2019 & 2020 \\
\hline$<0.000$ & Excellent & 49.39 & 49.29 & 47.57 & 37.41 \\
0.000 to 0.005 & Good & 4.90 & 4.43 & 4.95 & 1.78 \\
0.005 to 0.010 & Normal & 4.88 & 4.27 & 4.66 & 1.92 \\
0.010 to 0.015 & Bad & 4.71 & 3.96 & 4.51 & 2.01 \\
0.015 to 0.020 & Worse & 4.51 & 3.82 & 4.53 & 2.01 \\
$>0.020$ & Worst & 31.60 & 34.23 & 33.77 & 54.87 \\
\hline
\end{tabular}

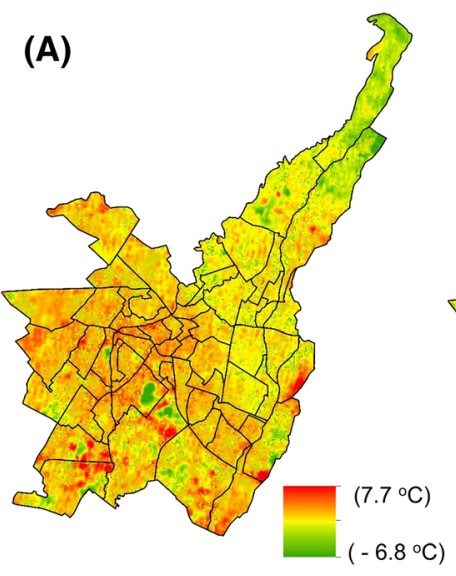

(a)

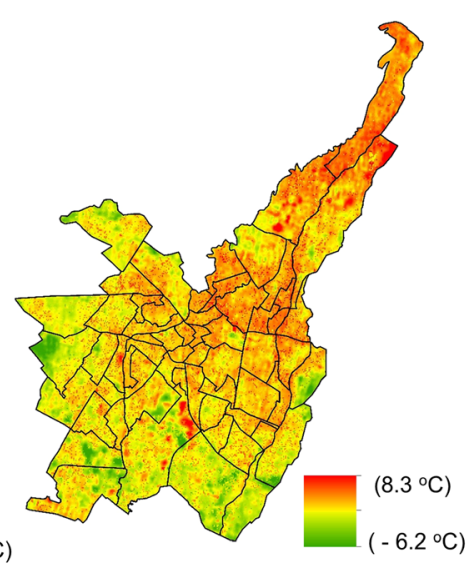

(b)

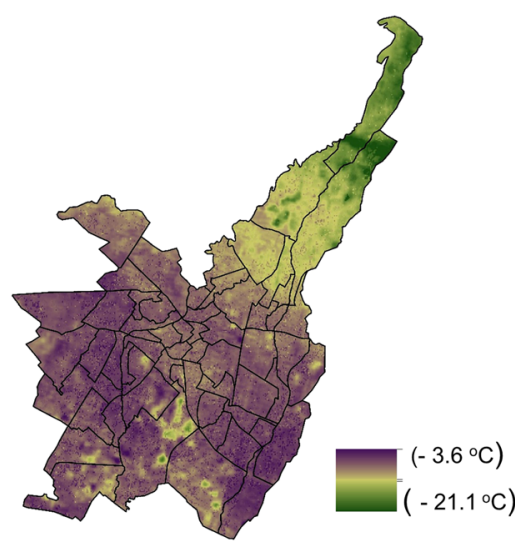

(c) $\square$ Ward boundary

\section{(B)}

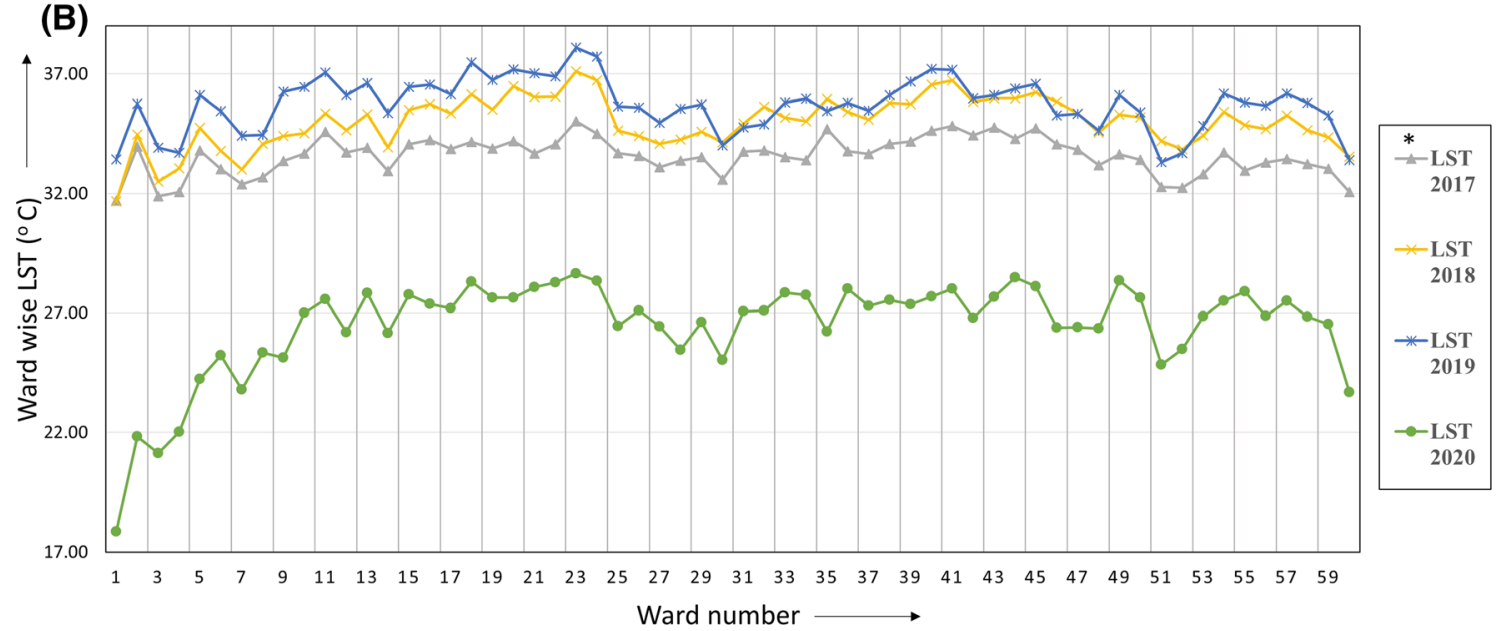

Fig. 3 a Change in LST during (a) 08 May 2017, (b) 25 April 2018, (c) 28 April 2019, (d) 14 April 2020. *LST denotes structural classwise LST on 08 May 2017. b Wardwise LST on (a) 08 May

same for the previous week of data acquisition for four multi-temporal Landsat imageries. Thus, urban parameters and land cover were considered the significant factors for the changing pattern of LST during the entire time period. Figure $3 \mathrm{a}$ and $\mathrm{b}$ shows that there has been an overall decrease in the LST values of all wards in year 2020 (i.e. the lockdown period). However, the standard deviation in wardwise LST values was largest in year 2020 compared to
2017, (b) 25 April 2018, (c) 28 April 2019, (d) 14 April 2020. *LST denotes structural classwise LST on 08 May 2017

Table 2 Standard deviation in wardwise LST values on 08 May 2017, 25 April 2018, 28 April 2019 and 14 April 2020

\begin{tabular}{lllll}
\hline Year & 2017 & 2018 & 2019 & 2020 \\
\hline$\sigma$ & 0.77 & 1.05 & 1.09 & 1.97 \\
\hline
\end{tabular}

where $\sigma$ denotes the standard deviation of wardwise LST values 
previous three years (Table 2). During period C, wards 1, 2, 3 and 4 had the maximum decrease in LST values (refer Fig. 3a and b). The wardwise LST and other descriptive statistics are as follows,

a. 08 May 2017: The minimum and maximum LST values were in ward $1\left(31.7^{\circ} \mathrm{C}\right)$ and ward 23 $\left(35.0^{\circ} \mathrm{C}\right)$, respectively, while the mean LST was $33.6{ }^{\circ} \mathrm{C}$ with a standard deviation of 0.77 (Fig. 2 and Table2)

b. 25 April 2018: The minimum and maximum LST values were in ward $1\left(31.7^{\circ} \mathrm{C}\right)$ and ward 23 $\left(37.1^{\circ} \mathrm{C}\right)$, respectively, while the mean LST was $35.0^{\circ} \mathrm{C}$ with a standard deviation of 1.05 (Fig. 2 and Table2)

c. 28 April 2019: The minimum and maximum LST values were ward $51\left(33.3^{\circ} \mathrm{C}\right)$ and ward $23\left(38.1^{\circ} \mathrm{C}\right)$, respectively, while the mean LST was $35.7^{\circ} \mathrm{C}$ with a standard deviation of 1.09 (Fig. 2 and Table2).

d. 14 April 2020: The minimum and maximum LST values were ward $1\left(17.8^{\circ} \mathrm{C}\right)$ and ward $23\left(28.6^{\circ} \mathrm{C}\right)$, respectively, while the mean LST was $26.5^{\circ} \mathrm{C}$ with a standard deviation of 1.97 (Fig. 2 and Table2).

Validation of LST values: Since there was no ground validation data available, the maximum, minimum and monthly average air temperature data of month April 2020, 2019, 2018 and 2017 months were taken from the website www.timeanddate.com (Table 3). The maximum temperature was $36{ }^{\circ} \mathrm{C}$ in year 2017 and 2018 which increased to $38{ }^{\circ} \mathrm{C}$ in 2019 and then decreased to $35^{\circ} \mathrm{C}$ in 2020 . The minimum temperature was $9{ }^{\circ} \mathrm{C}$ in $2017,15^{\circ} \mathrm{C}$ in year 2018, 2019 and $14{ }^{\circ} \mathrm{C}$ in 2020 . The monthly average temperature was $26^{\circ} \mathrm{C}, 26^{\circ} \mathrm{C}$ and $25^{\circ} \mathrm{C}$ in year 2017 , 2018 and 2019 , respectively, while it was $24{ }^{\circ} \mathrm{C}$ in year 2020. The least value of maximum, minimum and average temperature was found in April 2020 which correlated well with LST values retrieved in April 2020.

Table 3 Temperature data of April 2017, 2018, 2019 and 2020 used for the validation of LST values retrieved using RTE algorithm (Source website: www.timeanddate.com)

\begin{tabular}{llllll}
\hline & & & & & \\
\cline { 1 - 3 } \cline { 5 - 6 } Month: April & & 2017 & 2018 & 2019 & 2020 \\
\hline Maximum temperature $\left({ }^{\circ} \mathrm{C}\right)$ & 36 & 36 & 38 & 35 \\
Minimum temperature $\left({ }^{\circ} \mathrm{C}\right)$ & 9 & 15 & 15 & 14 \\
Monthly average temperature $\left({ }^{\circ} \mathrm{C}\right)$ & 26 & 26 & 25 & 24 \\
\hline
\end{tabular}

\section{Hot Spot Analysis Using Getis Ord GI Statistic}

Getis Ord GI ${ }^{*}$ statistic was used to describe the phenomena of clustering of high LST values (hot spots) and low LST values (cold spots) in the study area (Tran et al. 2017; Ord and Getis, 1995). A single high LST value could not qualify as a hot spot; to qualify as a hot spot, the high LST value should also be surrounded by other high LST values. The output of the GI* statistic is a z-score; higher positive z-score shows more intense clustering of high values (hot spot), and a smaller negative $\mathrm{z}$ score represents more intense clusters of low values (cold spot). Thus, GI statistic gives a better understanding of temporal LST patterns rather than focusing only on the absolute high or low LST values. In the present study, hot and cold spots with more than $95 \%$ confidence level were considered. Detailed discussion on GI* statistic can be found in ESRI (2016). The wardwise distribution of hot and cold spots in year 2017, 2018, 2019 and 2020 is shown in Fig. 4. Wards which were consistently hot or cold spot during year 2017, 2018, 2019 and 2020 are shown in Fig. 5.

\section{Wardwise Distribution of Urban Spatial Structure Classes}

The four urban spatial structure classes were delineated using the methodology discussed in Sect. 3.3. The wardwise distribution of the four structural classes is shown in Fig. 6. It can be seen that in the centre of city, south, south east and west part of the city there is high urban density (i.e. ward 41 to 60 , refer Fig. 6 and 1b), the primary reason being the availability of ample flat terrain and a dense road network with national and state highways leading to other major urban centres, viz. Delhi, Haridwar and Rishikesh. The medium- and low-density classes are located in the north of the city (i.e. ward no 1 and 2, refer Fig. 6 and 1b) where the terrain is hilly in nature and surrounded by reserve forest. The open spaces are situated in the north and south portion of the study area (i.e. ward no $1-9$, refer Fig. 6 and 1b). As discussed in Sect. 2, the strategic areas and water bodies present in Dehradun city were masked out.

\section{Temporal Analysis of LST Values in Each of the Four Urban Structure Classes}

a. Urban high density: The maximum LST in high-density built-up was $35.6{ }^{\circ} \mathrm{C}$ (in year 2019), and the minimum was $26.6{ }^{\circ} \mathrm{C}$ (in year 2020). The value of standard deviation for LST values in high-urban-density class was 1.36 and 1.87 for year 2019 and 2020, respectively (Fig. 7 and Table 4). 


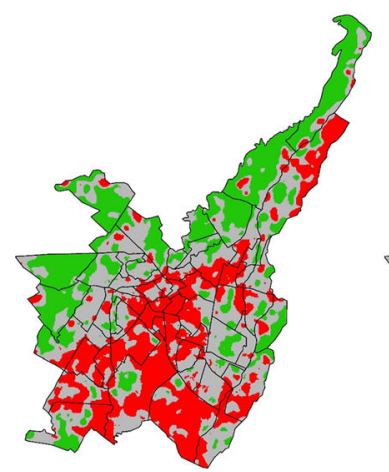

(a)

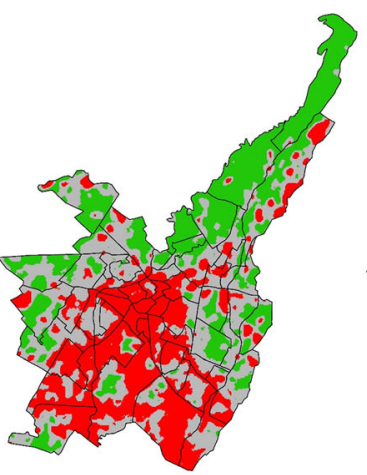

(b)

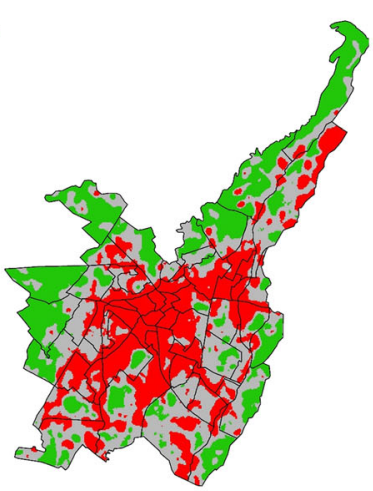

(c)

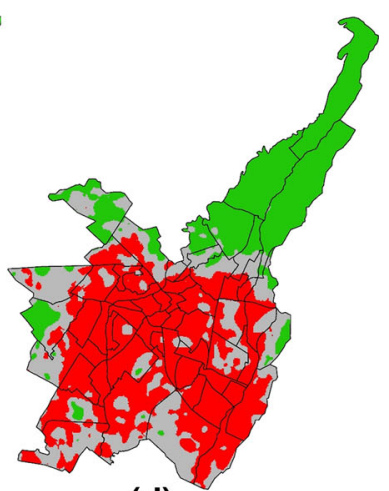

(d)

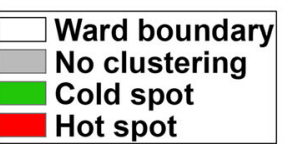

Fig. 4 Wardwise hot and cold spot distribution in Dehradun city a 08 May 2017, (b) 25 April 2018, (c) 28 April 2019, (c) (d) 14 April 2020

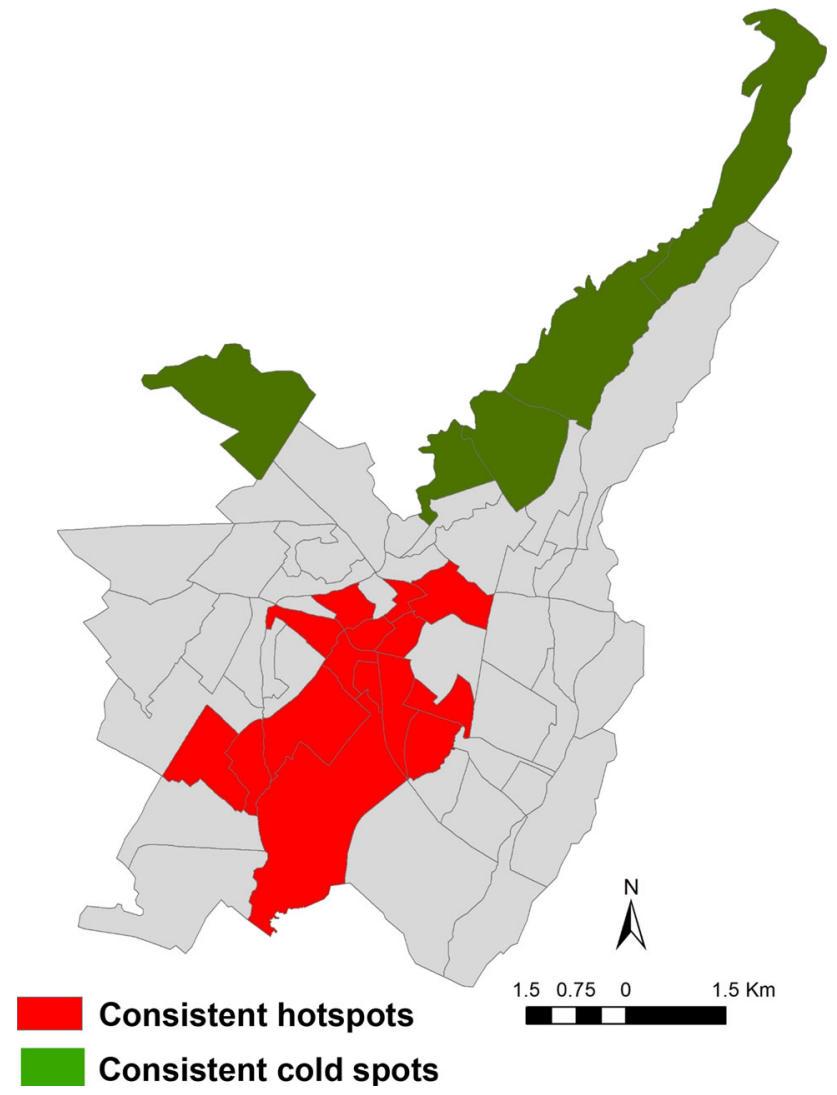

Fig. 5 Consistent hot and cold spots

b. Urban medium density: The maximum LST in medium-density built-up was $34.8^{\circ} \mathrm{C}$ (in year 2019), and the minimum was $21.8^{\circ} \mathrm{C}$ (in year 2020). The value of standard deviation for LST values in medium urban density was 1.60 and 3.41 , respectively (Fig. 7 and Table 4).

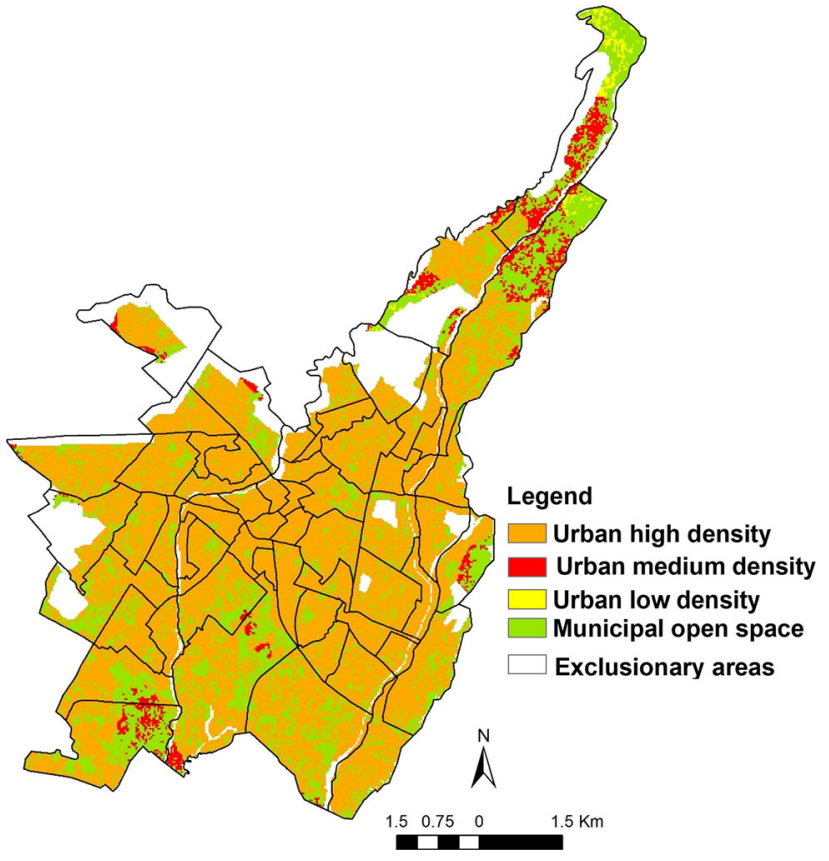

Fig. 6 Wardwise spatial distribution of urban structural classes in Dehradun city-2020

c. Urban low density: The maximum LST in low-density built-up was $34.1^{\circ} \mathrm{C}$ (in year 2019), and the minimum was $18.7^{\circ} \mathrm{C}$ (in year 2020). The value of standard deviation for LST in low urban density was 1.99 and 1.39, respectively (Fig. 7 and Table 4).

d. Municipal open space: The maximum LST in open space was $35.2{ }^{\circ} \mathrm{C}$ (in year 2019), and the minimum was $24.5^{\circ} \mathrm{C}$ (in 2020). The value of standard deviation for LST in open space class was 2.84 and 4.48, respectively (Fig. 7 and Table 4). 


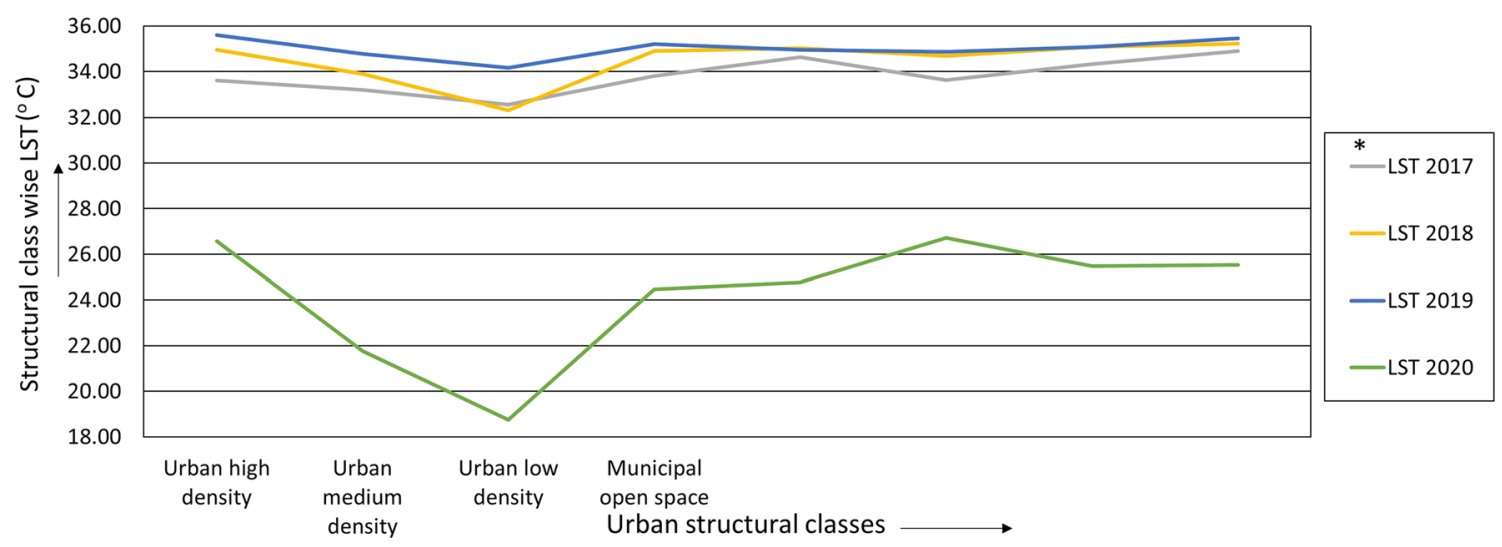

Fig. 7 LST values in different structural classes on (a) 08 May 2017, (b) 25 April 2018, (c) 28 April 2019, (d) 14 April 2020. *LST denotes structural classwise LST on 08 May 2017

Table 4 Standard deviation in LST values for different structural classes on 08 May 2017, 25 April 2018, 28 April 2019 and 14 April 2020

\begin{tabular}{lllll}
\hline & Urban high density & Urban medium density & Urban low density & Municipal open space \\
\hline$\sigma_{2017}$ & 1.15 & 1.72 & 1.89 & 1.89 \\
$\sigma_{2018}$ & 1.38 & 2.17 & 1.76 & 2.09 \\
$\sigma_{2019}$ & 1.36 & 1.6 & 1.99 & 1.93 \\
$\sigma_{2020}$ & 1.87 & 3.41 & 1.39 & 3.23 \\
\hline
\end{tabular}

where $\sigma_{2017}$ denotes the standard deviation in LST values for different structural classes on 08 May 2017
Thus, it can be summarized that maximum standard deviation in LST values was found in year 2020 in medium-urban-density class (i.e. 3.41) and in open space class (i.e. 3.23).

\section{Urban Thermal Field Variance Index (UTFVI)}

The UTFVI was calculated for the four years using Eq. (7). The UTFVI values were then classified into six EEI classes which represented the level of thermal comfort. Table 1 depicts the percentage of area under each of the six EEI classes in the respective four years. Figure 8 and Table 1 show that primarily Dehradun city has two extreme categories for ecological evaluation: the excellent category $(\mathrm{UTFVI}<0)$ and the worst category (UTFVI $>0.02$ ), while the rest of the categories occupied very less area. Temporal analysis of the EEI values revealed that,

a. Ten wards (10) had excellent EEI in all the four years. These wards had a high proportion of open space (i.e. from 34-56\%) along with urban high and medium built-up classes (Fig. 9a).

b. Twenty wards (20) had worst EEI on all the four years. These wards had a very high proportion of high builtup density (i.e. from 67-93\%), while the open space varied from $29-7 \%$ (Fig. 9b).

c. Seven wards (7) had worst EEI on 14 April 2020 (postCOVID lockdown) and excellent EEI (pre-COVID lockdown) in rest of three years, these wards also had a high proportion of high built-up density (i.e. from 65-90\%), while the open space varied from $35-10 \%$ and the medium- and low-urban-density classes had a negligible proportion (Fig. 9c).

\section{Discussion}

Dehradun city, which is a major administrative, commercial and cultural city of Uttarakhand, has undergone rapid urbanization in the last decade, which entails anthropogenically induced land-use and land-cover (LULC) changes, mainly due to the transition of natural landscapes to build terrains. This increasing march of mortar and cement has modified the thermal characteristics of the urban area which coupled with near-ground anthropogenic sources of heat has resulted in elevated LST in urban areas compared to the surrounding rural areas. These elevated levels of LST have resulted in ecological degradation and reduced level of human comfort. In the present study, the LST patterns and its relationship with the existing built form (expressed in the form of built-up density) was analysed at the ward level especially with reference to the lockdown during COVID 19. The ward was taken as the basic unit for analyses as it is the smallest urban unit at 


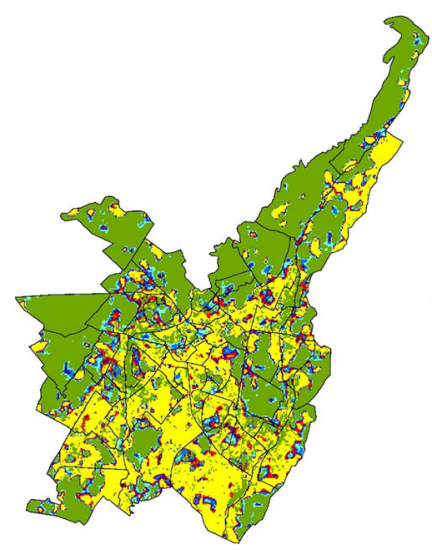

(a)

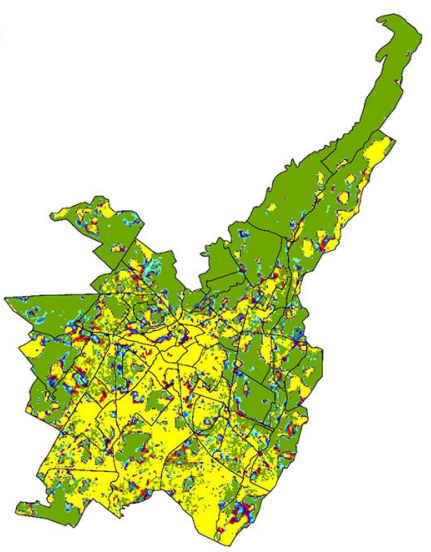

(b)

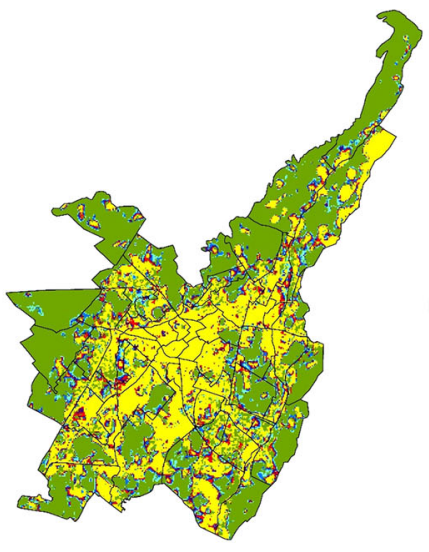

(c)

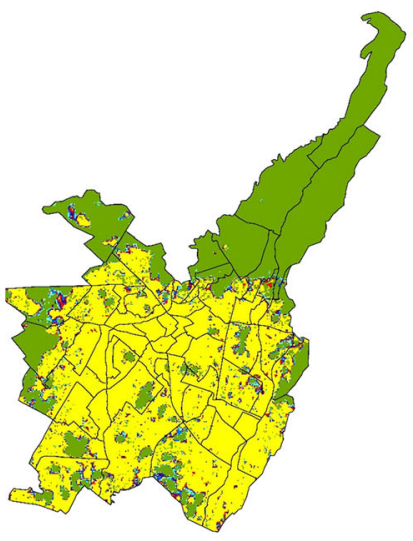

(d)

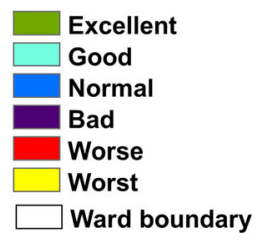

Fig. 8 Wardwise EEI distribution in Dehradun city (a) 08 May 2017, (b) 25 April 2018, (c) 28 April 2019, (c) (d) 14 April 2020

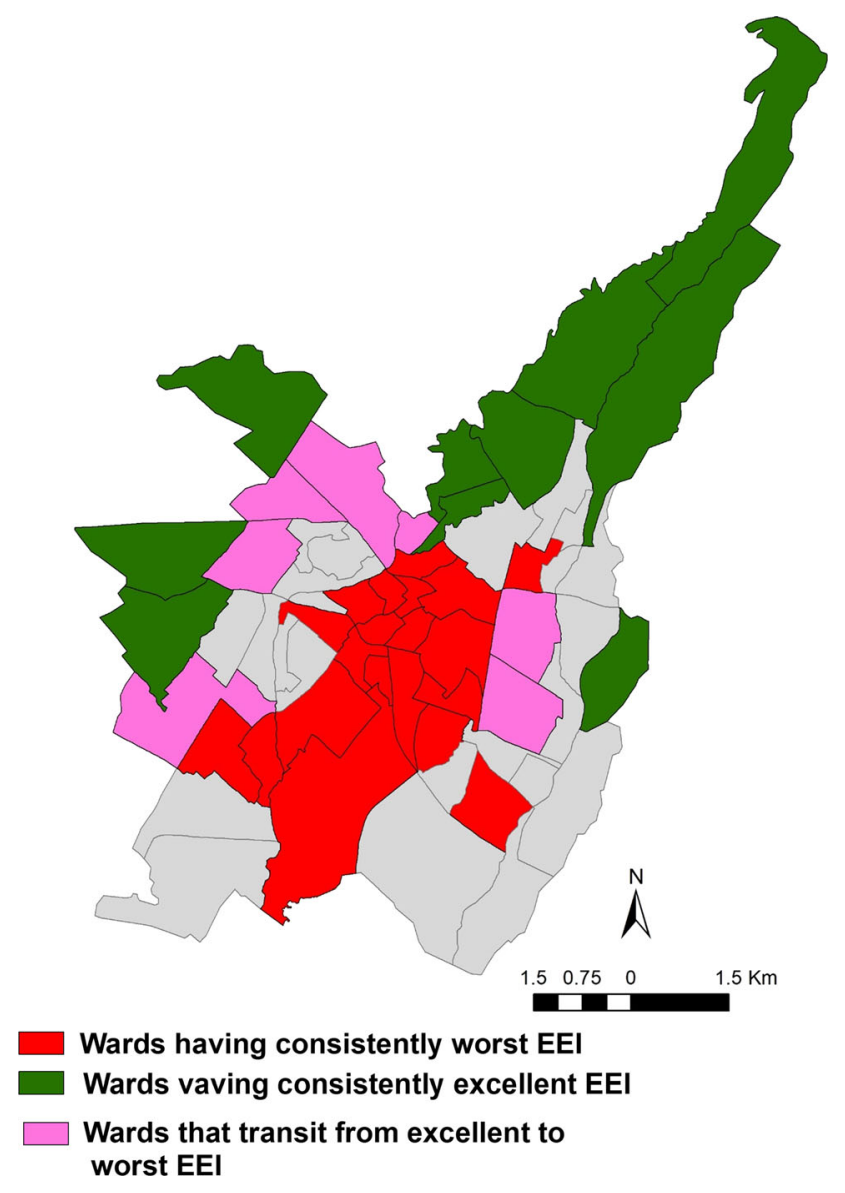

Fig. 9 Wards with consistent EEI class and transition from excellent to worst EEI class which all socio-economic and physical data are aggregated in Indian cities.

\section{LST Retrieval}

In order to contain the outbreak of COVID 19 epidemic, Dehradun city was put under a lockdown from 25 March 2020 till 14 April 2020. Hence, due to reduced socioeconomic activities the near-surface anthropogenic emission of thermal energy and air pollution was significantly reduced. For evaluating the effect of COVID lockdown on thermal environment, the LST in Dehradun city on 14 April 2020 was retrieved from TIRS data and compared with the near anniversary LST dates 28 April 2019, (c) 25 April 2018 and (d) 08 May 2017. The LST retrieval was done using the RTE method due to its simplicity and ease of implementation. Atmospheric Correction Parameter Calculator (ACPC) which is located on the web at https:// landsat.gsfc.nasa.gov/atm_corr was used for estimating the values of $T, L \downarrow_{\mathrm{atm}}, L \uparrow_{\mathrm{atm}}$. ACPC uses MODTRAN and NCEP data to simulate $T, L \downarrow_{\mathrm{atm}}$ and $L \uparrow_{\mathrm{atm}}$. Yu et al. (2014), also reported that interpolated NCEP data were good for local simulation of the three atmospheric parameters. The LSE $\left(\varepsilon_{\lambda}\right)$ was calculated using the NDVI threshold method (NDVI ${ }^{\mathrm{THM}}$ ), compared to other emissivity estimation methods (viz. classification-based emissivity and day/night temperature-independent spectral indices). $\mathrm{NDVI}^{\mathrm{THM}}$ is simple, has less data requirement and has already been applied to various sensors with access to VNIR data (Yu et al. 2014; Sobrino et al. 2008; Griend and Owe 1993; Momeni and Saradjian 2007). Since the present study is 
based on the comparison of LST values on four anniversary dates, the validation of LST values was done using the temperature data from website www.timeanddate.com. The temperature value showed a decreasing trend from year 2017, 2018, 2019 to 2020 similar to the LST values derived using the RTE algorithm.

\section{Analysis of Wardwise LST}

The analysis of LST values (Fig. 2) revealed that the mean LST over Dehradun city was $33.6{ }^{\circ} \mathrm{C}, 34.9^{\circ} \mathrm{C}$ and $35.7^{\circ} \mathrm{C}$ in year 2017,2018 and 2019 which reduced to $26.5^{\circ} \mathrm{C}$ in year 2020. The standard deviation in LST values was 0.77 , 1.05 and 1.09 in year 2017, 2018 and 2019 which increased to 1.97 in year 2020 (Table 2). During the COVID lockdown, due to restricted vehicular movement and the absence of commercial and industrial activities the pollution level was considerably less. These reduced pollution levels led to reduction in greenhouse effect which allowed long wave radiation to escape, and thus, the mean LST values over the Dehradun city were less compared to the previous years. Ward 1 which has a large proportion of vacant/vegetated land (56.68\%) and less proportion of urban high density $(6.96 \%)$ experienced the maximum decrease in LST (46.6\%); during period C (i.e. 28 April 2019-14 April 2020), the possible reasons could be,

(a) Increased evapotranspiration rate due to large vegetation proportion and increased solar irradiance due to reduced pollution levels.

(b) Reduced greenhouse effect.

(c) The absence of urban canyons as most of the built-up was of medium and low density.

On the other hand, ward 49 which had the minimum decrease in mean LST (i.e. 21.5\%) during period C had $93.97 \%$ of its area under urban high-density class and $6.03 \%$ of its area under open space. High built-up density and urban geometry (urban canyons, reduced sky view factor) resulted in more heat entrapment, which resulted in elevated LST levels and was one of the reasons for less decrease in LST values.

Figure 3a and Fig. 6 show that wards which were located in the city core with high urban density had relatively less decrease in temperature compared to the wards in the north which had a relatively more proportion of open space, urban medium- and low-urban-density classes.

\section{Hot Spot Analysis}

The hot and cold spots were delineated based on Getis Ord GI* statistic and represent the clustering of high and low LST values. Table 5 shows that the number of hot spots has increased from 19 in year 2017 to 42 in year 2020. The
Table 5 Number of hot and cold spots on 08 May 2017, 25 April 2018, 28 April 2019 and 14 April 2020

\begin{tabular}{lllll}
\hline Year & 2017 & 2018 & 2019 & 2020 \\
\hline No. of hot spot wards & 19 & 24 & 30 & 42 \\
No. of cold spot wards & 9 & 9 & 10 & 8 \\
\hline
\end{tabular}

increase in number of hot spots can be attributed to the increasing value of standard deviation (i.e. dispersion) in LST values which were 0.77 in 2017, 1.05 in 2018, 1.09 in 2019 and 1.97 in 2020. Due to this increasing dispersion in dataset, the clustering of high LST values was more pronounced compared to previous years when the dispersion in LST values was less. For hot spot analysis, it is the dispersion in LST values, which is crucial than the individual LST values. Hence, hot spot analysis using Getis Ord GI* statistic is an appropriate technique to analyse the LST patterns through time. Tran et al. (2017) also reported that the effect of different LST values through time is reduced by using hot spot analysis. The spatial distribution of hot spots is shown in Fig. 3. The hot spots were concentrated mainly in the city core, and the southern part and the northern part of study had a concentration of cold spots. The wards which were consistently hot spots in all the four years are displayed in Fig. 5.

\section{Urban Thermal Field Variance Index (UTFVI)}

The UTFVI values were used for the ecological evaluation of LST in Dehradun city. Table 1 shows that Dehradun city has two extreme EEI categories, namely the excellent $(\mathrm{UTFVI}<0$ ) and the worst category (UTFVI $>0.02$ ). The area covered by excellent EEI was $49.39 \%$ in year 2017 which reduced to $37.41 \%$ in year 2020 , while the area under worst EEI category increased from $31.60 \%$ in 2017 to $54.87 \%$ in 2020 (Table 1). As evident from Eq. 7, UTFVI is the ratio of $\left(T_{\mathrm{S}}-T_{\text {mean }}\right)$ to $T_{\text {mean }}$; hence, the greater the dispersion in dataset, the larger will be the value of UTFVI and the greater the outcome will be, poorer will be the EEI index (Table 1).

Figure 9 depicts the wards which were consistently in excellent or worst EEI category during the four years. Wards which were in consistently worst EEI category had a high proportion of urban high-density class and were situated in the city core. The consistent excellent EEI category wards had a high proportion of open space, mediumand low-built-density classes and these wards were situated in the north and west portion of the study area (refer Fig. 6, 8 and 9). 


\section{Limitation of Study}

(a) To avoid the problems of different seasons and months, near anniversary Landsat satellite image were used, viz. (a) 14 April 2020, (b) 28 April 2019, (c) 25 April 2018 and (d) 08 May 2017, with less than $10 \%$ cloud coverage.

(b) The precipitation remained almost the same during the previous week of data acquisition on all abovementioned four dates

(c) The spatial distribution and fraction of built-up density classes in the Dehradun city was more or less same in year 2020, 2019, 2018 and 2017.

Thus, by keeping the metrological and land-cover parameters constant as far as possible it was assumed that during COVID lockdown the reduction in LST was due to the absence of near-surface anthropogenic source of heat (i.e. vehicular traffic, industrial and commercial activities) and reduced pollution levels. (Reduction in greenhouse effect allowed long wave radiation to escape, and thus, the mean LST values over the Dehradun city were less compared to the previous years.) The effect of these factors was seen in the form of average reduction in LST values during the lockdown period (refer Sect. 4.1). The present article thus aims to explain the differential reduction in LST values over various built-up density classes as a function of urban form and open spaces.

\section{Conclusion}

In Dehradun city, wards which are located in the northern part had the maximum decrease in LST during period C and these wards were also consistently qualified as cold spots and excellent EEI class in all the four years. Primarily, a large proportion of area in these wards was under open space, and secondly, the built-up development was in the form of medium and low density, due to which the problems of urban geometry (i.e. urban canyons) was not dominant in these areas. On the contrary, wards located in city core were dominated by high-density developments, due to which the sky view factor was reduced and more heat entrapment leads to elevated LST levels; secondly, the density of vegetation was less in these areas which led to reduced rate of evapotranspiration. Further it is also inferred that it is necessary to consider the effects of spatial autocorrelation in temporal comparison of LST patterns. From the perspective of urban planning, it is recommended that planners pay attention to what kind of urban growth patterns aggravate or mitigate the LST patterns. The methodology presented in this paper can also be applied to other Indian cities and can serve as a tool for taking rational decisions for sustainable urban planning.

Acknowledgements We gratefully acknowledge Department of Science and Technology, Government of India for providing support through the INSPIRE fellowship to Ms. Garima Nautiyal (second author), Doon University.

\section{References}

Ali, J. M., Marsha, S. H., \& Smith, M. J. (2017). A comparison between London and Baghdad surface urban heat islands and possible engineering mitigation solutions. Sustainable Cities and Society, 29, 159-168.

Ao, K. F., Ngo, H. T. M. (2000). GIS analysis of Vancouver's urban heat island. Retrieved March 20, 2020 from https://www.geog. ubc.ca/courses/klink/g470/class00/kfao/abstract.html.

Anderson, J. R., Hardy, E. E., Roach, J. T., \& Witmer, R. E. (1976). A land use and land cover classification system for use with remote sensor data. USGS Professional Paper 964, USA.

Angel, S., Parent, J., \& Civco, D. L. (2012). The fragmentation of urban landscapes: global evidence of a key attribute of the spatial structure of cities, 1990-2000. Environment and Urbanization, 24(1), 249-283.

Arora, M. K. (2002). Land cover classification from remote sensing data.GIS@development, 6(3),24-25.

Barsi, J. A., Barker, J. L., \& Schott, J. R. (2003). An Atmospheric Correction Parameter Calculator for a single thermal band earthsensing instrument. In IEEE International Geoscience and Remote Sensing Symposium. Proceedings (IEEE Cat. No.03CH37477). https://doi.org/10.1109/igarss.2003.1294665.

Bera, B., Bhattacharjee, S., Shit, P. K., et al. (2020). Significant impacts of COVID-19 lockdown on urban air pollution in Kolkata (India) and amelioration of environmental health. Environment, Development and Sustainability. https://doi.org/ 10.1007/s10668-020-00898-5.

Census of India (2011). Office of the Registrar General and Census Commissioner, New Delhi, India. Retrieved June 13, 2019 from https://censusindia.gov.in.

Chauhan, A., \& Singh, R. P. (2020). Decline in PM2.5 concentrations over major cities around the world associated with COVID-19. Environmental Research, 187, 109634.

Congalton, R. G. (1991). A review of assessing the accuracy of classifications of remotely sensed data. Remote Sensing of Environment, 37, 35-46.

Congalton, R. G., \& Green, K. (1999). Assessing the Accuracy of Remotely Sensed Data: Principles and Practices. Florida, USA: CRC Press Inc.

ESRI (2016). How Hot Spot Analysis (Getis-Ord Gi*) works. Retrieved April 16, 2020 from https://proarcgis.com/en/proapp/tool-reference/spatial-statistics/h-how-hot-spot-analysisgetis-ord-gispatial-stati.htm pro-app/tool-reference/spatialstatistics/h-how-hot-spot-analysis-getis-ord-gispatial-stati.htm.

Fan, F., Wang, Y., \& Wang, Z. (2008). Temporal and spatial change detecting (1998-2003) and predicting of land use and land cover in Core corridor of Pearl River Delta (China) by using TM and ETM+ images. Environmental Monitoring and Assessment, 137, 127-147.

Gallo, K. P., McNab, A. L., Karl, T. R., Brown, J. F., Hood, J. J., \& Tarpley, J. D. (1993). The use of NOAA AVHRR data for assessment of the urban heat island effect. Journal of Applied Meteorology, 32(5), 899-908. 
Ghosh, S., Das, A., Hembram, T. K., Saha, S., Pradhan, B., \& Alamri, A. M. (2020). Impact of COVID-19 induced lockdown on environmental quality in four indian megacities using landsat 8 OLI and TIRS-derived data and mamdani fuzzy logic modelling approach. Sustainability, 12, 5464. https://doi.org/10.3390/ su12135464.

Guha, S., Govil, H., Dey, A., \& Gill, N. (2018). Analytical study of land surface temperature with NDVI and NDBI using Landsat 8 OLI and TIRS data in Florence and Naples city, Italy. European Journal of Remote Sensing, 51(1), 667-678. https://doi.org/10. 1080/22797254.2018.1474494.

Guha, S., Govil, H., \& Mukherjee, S. (2017). Dynamic analysis and ecological evaluation of urban heat islands in Raipur city India. Journal of Applied Remote Sensing, 11(3), 36020. https://doi. org/10.1117/1.JRS.11.036020.

Guo, G., Wu, Z., Xiao, R., Chen, Y., Liu, X., \& Zhang, X. (2015). Impacts of urban biophysical composition on land surface temperature in urban heat island clusters. Landscape and Urban Planning, 135, 1-10.

Gupta, N., Tomar, A., \& Kumar, V. (2020). The effect of COVID-19 lockdown on the air environment in India. Global Journal of Environmental Science and Management, 6(Special Issue (Covid-19)), 31-40.

Imhoff, M. L., Zhang, P., Wolfe, R. E., \& Bounoua, L. (2010). Remote sensing of the urban heat island effect across biomes in the continental USA. Remote Sensing of Environment, 114, 504-513.

Jason et al. (2009) Measuring spatial patterns and trends in urban development . Retrieved June 15, 2019 from https://clear.uconn. edu/tools/ugat/pubs.htm.

Kant, Y., Mitra, D., \& Chauhan, P. (2020). Space-based observations on the impact of COVID-19-induced lockdown on aerosols over India. Current Science, 119(3), 539-544. https://doi.org/10.3389/ fcimb.2018.00343.7.

Kikon, N., Singh, P., Singh, S. K., \& Vyas, A. (2016). Assessment of urban heat islands (UHI) of Noida City, India using multitemporal satellite data. Sustainable Cities and Society, 22, 19-28.

Kotnala, G., Mandal, T. K., Sharma, S. K., \& Kotnala, R. K. (2020). Emergence of blue sky over Delhi due to Coronavirus disease (COVID-19) lockdown implications. Aerosol Science and Engineering. https://doi.org/10.1007/s41810-020-00062-6.

Kumar, P., Hama, S., Omidvarborna, H., Sharma, A., Sahani, J., Abhijith, K. V., et al. (2020). Temporary reduction in fine particulate matter due to 'anthropogenic emissions switch-off' during COVID-19 lockdown in Indian cities. Sustainable Cities and Society. https://doi.org/10.1016/j.scs.2020.102382.

Kumar, S. (2020). Effect of meteorological parameters on spread of COVID-19 in India and air quality during lockdown. Science of the Total Environment, 745, 141021.

Lal, P., Kumar, A., Kumar, S., Kumari, S., Saikia, P., Dayanandan, A., et al. (2020). The dark cloud with a silver lining: assessing the impact of the SARS COVID-19 pandemic on the global environment. The Science of the Total Environment, 732, 139297.

Lokhandwala, S., \& Gautam, P. (2020). Indirect impact of COVID-19 on environment: A brief study in Indian context. Environmental research, 188, 109807.

Mahato, S., Pal, S. \& Ghosh, K. G. (2020). Effect of lockdown amid COVID-19 pandemic on air quality of the megacity Delhi, India. The Science of the Total Environment, 730, Article 139086.

Mallick, J., Singh, C. K., Shashtri, S., Rahman, A., \& Mukherjee, S. (2012). Land surface emissivity retrieval based on moisture index from LANDSAT TM satellite data over heterogeneous surfaces of Delhi city. International Journal of Applied Earth
Observation and Geoinformation, 19, 348-358. https://doi.org/ 10.1016/j.jag.2012.06.002.

Mallick, J., Rahman, A., \& Singh, C. K. (2013). Modeling urban heat islands in heterogeneous land surface and its correlation with impervious surface area by using night-time ASTER satellite data in highly urbanizing city, Delhi-India. Advances in Space Research, 52(4), 639-655. https://doi.org/10.1016/j.asr.2013.04. 025.

Mandal, I., \& Pal, S. (2020). COVID-19 pandemic persuaded lockdown effects on environment over stone quarrying and crushing areas. The Science of the Total environment, 732, 139281.

Mather, P. M. (1999). Computer processing of remotely sensed images: An introduction. Chichester: John Wiley \& Sons.

Mathew, A., Khandelwal, S., \& Kaul, N. (2016). Spatial and temporal variations of urban heat island effect and the effect of percentage impervious surface area and elevation on land surface temperature: Study of Chandigarh City, India. Sustainable cities and society. https://doi.org/10.1016/j.scs.2016.06.018.

Mathew, A., Khandelwal, S., \& Kaul, N. (2017). Investigating spatial and seasonal variations of urban heat island effect over Jaipur city and its relationship with vegetation, urbanization and elevation parameters. Sustainable cities and society. https://doi. org/10.1016/j.scs.2017.07.013.

Mitra, A., Chaudhuri, T. R., Mitra, A., Pramanick, P., \& Zaman, S. (2020). Impact of COVID-19 related shutdown on atmospheric carbon dioxide level in the city of Kolkata. Parana Journal of Science and Education, 6, 84-92.

Momeni, M., \& Saradjian, M. (2007). Evaluating NDVI-based emissivities of MODIS bands 31 and 32 using emissivities derived by day/night LST algorithm. Remote Sensing of Environment, 106, 190-198.

Isaya Ndossi, M., \& Avdan, U. (2016). Application of open source coding technologies in the production of land surface temperature (LST) maps from landsat: A PyQGIS plugin. Remote Sensing, 8(5), 413. https://doi.org/10.3390/rs8050413.

Oke, T. R. (1982). The energetic basis of the urban heat island. Quarterly Journal of the Royal Meteorological Society, 108, $1-24$.

Ord, J. K., \& Getis, A. (1995). Local spatial autocorrelation statistics: distributional issues and an application. Geographical analysis, 27(4), 286-306.

Rahman, A., Aggarwal, S. P., Netzband, M., \& Fazal, S. (2011). Monitoring urban sprawl using remote sensing and gis techniques of a fast growing urban centre, India. IEEE Journal of Selected Topics in Applied Earth Observations and Remote Sensing, 4(1), 56-64. https://doi.org/10.1109/JSTARS.2010. 2084072.

Mukherjee, S., Joshi, P. K., \& Garg, R. D. (2017). Analysis of urban built-up areas and surface urban heat island using downscaled MODIS derived land surface temperature data. Geocarto International, 32(8), 900-918. https://doi.org/10.1080/10106049. 2016.1222634

Sharma, S., Zhang, M., Gao, J., Zhang, H., \& Kota, S. H. (2020). Effect of restricted emissions during COVID-19 on air quality in India. The Science of the Total Environment, 728, 138878.

Siddiqui, A., Halder, S., Chauhan, P., \& Kumar, P. (2020). COVID19 Pandemic and City-Level Nitrogen Dioxide $\left(\mathrm{NO}_{2}\right)$ Reduction for Urban Centres of India. Journal of the Indian Society of Remote Sensing. https://doi.org/10.1007/s12524-020-01130-7.

Sobrino, J., \& Raissouni, N. (2000). Toward remote sensing methods for land cover dynamic monitoring: Application to Morocco. International Journal of Remote Sensing, 21, 353-366.

Sobrino, J. A., Jiménez-Muñoz, J. C., \& Paolini, L. (2004). Land surface temperature retrieval from LANDSAT TM 5. Remote 
Sensing of Environment, 90(4), 434-440. https://doi.org/10. 1016/j.rse.2004.02.003.

Sobrino, J. A., \& Romaguera, M. (2004). Land surface temperature retrieval from MSG1-SEVIRI data. Remote Sensing of Environment, 92, 247-254.

Sobrino, J. A., Jiménez-Muñoz, J. C., Sòria, G., Romaguera, M., Guanter, L., Moreno, J., et al. (2008). Land surface emissivity retrieval from different VNIR and TIR sensors. IEEE Transactions on Geoscience and Remote Sensing, 46(2), 316-327. https://doi.org/10.1109/TGRS.2007.904834.

Selvam, S., Jesuraja, K., Venkatramanan, S., Chung, S. Y., Roy, P. D., Muthukumar, P., et al. (2020). Imprints of pandemic lockdown on subsurface water quality in the coastal industrial city of Tuticorin, south India: a revival perspective. Science of the Total Environment. https://doi.org/10.1016/j.scitotenv.2020.139848.

Srivastava, S., Kumar, A., Bauddh, K., Gautam, A. S., \& Kumar, S. (2020). 21-day lockdown in India dramatically reduced air pollution indices in Lucknow and New Delhi, India. Bulletin of Environmental Contamination and Toxicology. https://doi.org/ 10.1007/s00128-020-02895-w.

Tran, D. X., Pla, F., Latorre-Carmona, P., Myint, S. W., Caetano, M., \& Kieu, H. V. (2017). Characterizing the relationship between land use land cover change and land surface temperature. ISPRS Journal of Photogrammetry and Remote Sensing, 124, 119-132. https://doi.org/10.1016/j.isprsjprs.2017.01.001.

Vaibhav, G., Aggarwal, S. P., \& Chauhan, P. (2020). Changes in turbidity along Ganga River using Sentinel-2 satellite data during lockdown associated with COVID-19. Geomatics, Natural Hazards and Risk, 11(1), 1175-1195. https://doi.org/10. 1080/19475705.2020.1782482.

Van de Griend, A. A., \& Owe, M. (1993). On the relationship between thermal emissivity and the normalized difference vegetation index for natural surfaces. International Journal of
Remote Sensing, 14(6), 1119-1131. https://doi.org/10.1080/ 01431169308904400.

Wang, F., Qin, Z., Song, C., Tu, L., Karnieli, A., \& Zhao, S. (2015). An improved mono-window algorithm for land surface temperature retrieval from landsat 8 thermal infrared sensor data. Remote Sensing, 7(4), 4268-4289. https://doi.org/10.3390/ rs70404268.

Wang, Z.-H., \& Upreti, R. (2019). A scenario analysis of thermal environmental changes induced by urban growth in Colorado River Basin, USA. Landscape and Urban Planning, 181, 125-138. https://doi.org/10.1016/j.landurbplan.2018.10.002.

Xu, H., Lin, D., \& Tang, F. (2012). The impact of impervious surface development on land surface temperature in a subtropical city: Xiamen, China. International Journal of Climatology. https:// doi.org/10.1002/joc.3554.

Yuan, F., \& Bauer, M. E. (2007). Comparison of impervious surface area and normalized difference vegetation index as indicators of surface urban heat island effects in Landsat imagery. Remote Sensing of Environment, 106, 375-386.

Yu, X., Guo, X., \& Wu, Z. (2014). Land surface temperature retrieval from landsat 8 TIRS-comparison between radiative transfer equation-based method, split window algorithm and single channel method. Remote Sensing, 6(10), 9829-9852. https:// doi.org/10.3390/rs6109829.

Zhang, Y. (2006). Land surface temperature retrieval from CBERS02 IRMSS thermal infrared data and its applications in quantitative analysis of urban heat island effect. Journal of Remote Sensing, 10, 789-797.

Publisher's Note Springer Nature remains neutral with regard to jurisdictional claims in published maps and institutional affiliations. 